\title{
Estratégias de Enfrentamento Psicológico de Médicos Oncologistas Clínicos ${ }^{1}$
}

ARTIGO ORIGINAL

\author{
Débora Staub Cano ${ }^{2}$ \\ Faculdades Integradas de Taquara \\ Carmen Leontina Ojeda Ocampo Moré \\ Universidade Federal de Santa Catarina
}

\begin{abstract}
RESUMO - Esta pesquisa objetivou caracterizar as estratégias de enfrentamento psicológico utilizadas por médicos oncologistas. Foram observados e entrevistados doze oncologistas clínicos, que atuavam no sul do país. A análise dos dados seguiu os princípios da Teoria Fundamentada nos Dados. Foram construídas seis categorias de análises e sua denominação teve como referência a teoria de enfrentamento psicológico: (a) Focalizada no problema; (b) Focalizada na emoção; (c) Religiosidade/ Espiritualidade; (d) Suporte social; (e) Estratégia combinada; e (f) Autoavaliação de estratégias utilizadas. Os resultados apontam que os profissionais fazem uso de diversas estratégias de enfrentamento, evidenciando a necessidade de autorreflexão, apoio e suporte social, o que pode favorecer uma melhor adaptação às demandas, às exigências e ao reconhecimento de degaste emocional dessa especialidade profissional.
\end{abstract}

Palavras-chave: psico-oncologia, oncologia, pessoal médico, enfrentamento, coping

\section{Psychological Coping Strategies of Clinical Medical Oncologists}

\begin{abstract}
This work, aimed at characterizing psychological coping strategies used by clinical oncologists. Twelve clinical oncologists who worked in Southern Brazil were observed and interviewed. The analysis, based on Grounded Theory, resulted in six categories based on the theory of psychological coping: (a) Problem focused; (b) Emotion focused; (c) Religiosity / Spirituality; (d) Social support; (e) Combined strategy; and (f) Self-evaluation of the strategies used. The results indicate that the coping strategies of these professionals are diverse, which highlights the need for self-reflection and social support that may favor a better adaptation to the demands of the profession, requirements and the recognition of emotional distress that affect the oncologist practice.
\end{abstract}

Keywords: psyco-oncology, oncology, medical personnel, coping behavior, coping

O cotidiano de práticas dos médicos oncologistas clínicos, que se sustenta eminentemente na dimensão relacional médico-paciente-família, está permeado por metáforas que traduzem, de certa maneira, o sentido e as significações de como esses profissionais vivenciam essa especialidade. Assim, metáforas como a "figura de um salvador", uma "espécie de semideus" - como se pudessem dominar os limites entre a vida e a morte - desvelam as exigências de lidar com uma doença, ainda limitada no que se refere à cura (Cano, 2008).

Essas exigências, que envolvem o contato frequente com situações de doença, sofrimento e morte, bem como o lidar com incertezas e angústias - fruto da fragilidade humana - acrescido da necessidade de responder à mobilização emocional que isso acarreta, colocam o profissional da medicina diante de situações que lhe exigem estratégias e manejos psicológicos a fim de conviver e lidar com suas atividades diárias (Campos, 2005; L.A. Nogueira-Martins, 2003; M.C.F. Nogueira-Martins, 2001; Pitta, 2003). Cabe ressaltar que, mesmo sendo a medicina uma profissão que

1 O presente artigo é derivado da dissertação de mestrado "O profissional que está no fio entre a vida e a morte: vivências, concepções e estratégias de enfrentamento psicológico de médicos oncologistas", da primeira autora, sob orientação da segunda autora.

2 Endereço para correspondência: Rua Castro Alves 915/601, Rio Branco, Porto Alegre, RS, Brasil. CEP: 90430-131. E-mail: deborascano@ hotmail.com requer capacidades e destreza no trato social e pessoal, essas habilidades são desconsideradas quando do processo seletivo (Millan, Azevedo, Rossi, De Marco, Millan, \& Arruda, 2005).

Assim, para que consigam manejar e melhor conviver com a "parte subjetiva" de uma ciência, calcada no positivismo, que enfatiza, já em sua formação a separação disciplinar e a objetividade (Sá, 2000), os profissionais, são instigados a assumir um comportamento frio, reprimindo os sentimentos e emoções, em busca de uma atitude neutra. No entanto, acima de tudo, utilizam-se dessa "postura" como uma estratégia defensiva, na tentativa de não se deixarem envolver, criando uma espécie de proteção (Meleiro, 2005; Quintana, Rodrigues, Goi, \& Bassi, 2004).

Hanna, Marta e Santos (2011), em uma revisão da literatura, apontam que os profissionais da oncologia tendem a não querer se defrontar com a iminência da morte, em função do sofrimento que a mesma acarreta, o que corrobora para dificuldades na comunicação médico-paciente. Assim, não poucas vezes, observa-se a não comunicação do diagnóstico, como um modo de proteção utilizado pelo próprio médico para lidar com a sensação de impotência diante de suas limitações terapêuticas (Gomes, Silva, \& Mota, 2009). Inclusive, em pesquisa nacional realizada com médicos oncologistas, ficou evidenciado que muitos profissionais se isentam de comunicar o diagnóstico ou, ainda, optam por mentir, na tentativa de pouparem emocionalmente o paciente (Silva et al., 2011). 
Carvalho (2006), por sua vez, pondera que diferenças pessoais determinam reações distintas, mas afirma que, no contexto da prática oncológica, uma das formas de defesa pode ser o comportamento de "ir em frente", ou seja, o profissional não se atém àquilo que lhe passa, como se, agindo desse modo, criasse um anteparo ao desenvolvimento de sentimentos e emoções. $\mathrm{O}$ uso da despersonalização e o nivelamento dos pacientes, adotando-se a ideia de que são todos iguais, impedem o estabelecimento de vínculos específicos. Evita-se, assim, o contato com aquilo de subjetivo e característico que existe em cada paciente.

Nesse sentido, Graham (2000) destaca a importância do desenvolvimento de atividades e pesquisas que sustentem a busca pela qualidade de vida do profissional da oncologia, bem como considera vital conhecer os possíveis fatores de proteção e os recursos de que o médico dispõe para lidar com sua realidade cotidiana. De fato, conforme Lozano (2007), é necessário maior suporte e apoio aos médicos para que estejam aptos a lidar com as exigências e demandas de sua prática.

\section{Estratégias de Enfrentamento Psicológico e as Pesquisas no Contexto Médico}

O conjunto de estratégias e habilidades utilizadas pelas pessoas frente a situações consideradas adversas - por exemplo, o estresse - ou que exijam adaptação é denominado coping, termo que poderia ser compreendido, no sentido figurativo, como "enfrentar", "seguir em frente". Na perspectiva de Lazarus e Folkman (1984), coping é definido como um conjunto de esforços cognitivos e comportamentais utilizado pelos indivíduos em situações e demandas específicas (internas ou externas) que emanam de eventos causadores de estresse, sendo avaliadas como sobrecargas ou excessos aos recursos pessoais. $\mathrm{O}$ termo coping, apesar de não possuir uma tradução adequada para o português, uma vez que se relaciona tanto com aspectos psicológicos como comportamentais, tem sido comumente expresso na literatura nacional (Faria \& Seidl, 2005; Silva et al., 2016; Seidl, Tróccoli, \& Zannon, 2001; Zonta, Robles, \& Grosseman, 2006) através da expressão estratégias de enfrentamento psicológico, que será utilizada como sinônimo neste artigo.

Os autores classificam coping em duas categorias. A primeira diz respeito ao coping focalizado na emoção, que se define pelos esforços emanados para regular o estado emocional e pelas emoções associadas ao evento estressante. São esforços que visam alterar o estado emocional. Já o coping focalizado no problema caracteriza-se por um esforço no sentido de alterar a situação geradora de estresse, tentando modificá-la. Essas estratégias podem ser dirigidas (a) ao meio externo - tentando negociar ou gerenciar um conflito interpessoal, ou solicitando auxílio de outros para alterar alguma situação ou evento -, (b) bem como ao meio interno - buscando a ressignificação do evento estressor, procurando minimizar seus efeitos (Lazarus \& Folkman, 1984).

Desse modo, o estudo das estratégias de enfrentamento psicológico no contexto da medicina tem assumido significativa relevância, visto o grande impacto das demandas do trabalho médico no bem-estar e na saúde desses profissionais (Escribà-Agüir \& Bernabé-Munôz, 2002; Paris \& Omar, 2008). As pesquisas desenvolvidas evidenciam, por exemplo, a adoção de condutas passivas, de aceitação e de resignação frente às situações do exercício médico (Congrains, 1998; Jiménez, 2005), a necessidade de apoio social e emocional, em detrimento da busca de apoio na religiosidade (Blandin \& Araujo, 2005), a valorização e organização do tempo livre (Paris \& Omar, 2008), bem como a adoção de cuidados pessoais (Zonta, Robles, \& Grosseman, 2006).

Especificamente no contexto da oncologia, Roger, Abalo, Guerra e Pérez (2006) assinalaram que o grupo com maior desgaste profissional, indicando a prevalência da Síndrome de Burnout $^{1}$, utiliza mais comumente as estratégias de enfrentamento voltadas ao distanciamento e à evitação. Por outro lado, Trindade, Azambuja, Andrade e Garrafa (2007) evidenciaram que, à medida que os recursos terapêuticos se esgotam, os oncologistas parecem assumir uma atitude paternalista frente ao paciente. Em outro estudo, Glasberg et al. (2007) apontaram que, apesar da existência de suporte familiar, filiação religiosa e do cuidado em preservar as atividades de lazer e tempo para férias, os médicos referem fatores que indicam a presença da Síndrome de Burnout.

Entre as estratégias focadas na emoção, os médicos, apontam, em primeiro lugar, o uso de atividades distintas e desconexas do trabalho, como ócio e atividades esportivas. Na sequência, aparece a busca de apoio social, especialmente da família e amigos. Em terceiro lugar, está o consumo de fármacos e tabaco. No que se refere às estratégias focadas no problema, em primeiro lugar, aparece a aceitação de que a ciência médica não é exata e, em seguida, a busca por apoio instrumental, seja conversando com colegas ou consultando alguma bibliografia específica (Escribà-Agüir \& BernabéMunôz, 2002).

Sob essa ótica, esta pesquisa teve, como objetivo, caracterizar as estratégias de enfrentamento psicológico utilizadas pelos médicos oncologistas na sua prática cotidiana. Entende-se que é de suma importância refletir sobre a práxis médica, para que se possa subsidiar programas de atenção e cuidado a esse profissional, enfocando, principalmente, a prevenção de agravos relacionados ao estresse e a promoção da saúde.

\section{Método}

A pesquisa caracteriza-se por um estudo qualitativo de corte transversal, uma vez que analisa um momento específico da vida dos participantes. Bem como, descritivo e exploratório, na medida em que busca caracterizar e descrever aspectos da prática médica, considerando os significados, as opiniões, as experiências e as crenças contidas nas narrativas dos oncologistas (Sampieri, Collado, \& Lucio, 1991).

1 A síndrome de Burnout compreende três dimensões: exaustão emocional (esgotamento dos recursos emocionais do indivíduo), despersonalização (insensibilidade do profissional perante seus clientes e colegas, tratandoos de maneira muito impessoal) e redução da realização profissional (insatisfação com a profissão; Maslach, 1986). 


\section{Participantes}

Participaram desta pesquisa doze médicos oncologistas clínicos, que atuavam em um centro público de atendimento e pesquisa em oncologia, serviço de atenção terciária, referência no sul do país. Em relação ao sexo, sete eram homens, e cinco, mulheres; a idade variou entre 32 e 57 anos; dos homens, somente um era solteiro; das mulheres, três eram divorciadas, sendo que todos os demais eram casados. A experiência profissional em oncologia variou entre dois anos e meio e trinta anos; a maioria dos participantes tinha acima de dez anos de profissão. A escolha dessa especialidade justificou-se pois esses profissionais encontram-se mais vulneráveis a situações de estresse e estafa profissional (Roger, Abalo, Guerra, \& Pérez, 2006), sendo também os responsáveis tanto pela comunicação diagnóstica como pelo acompanhamento do paciente e de sua família.

\section{Procedimento e Instrumentos}

O projeto de pesquisa foi aprovado pelo Comitê de Ética e Pesquisa com Seres Humanos da Universidade Federal de Santa Catarina e pelo Comitê de Ética da instituição pesquisada, conforme as normas da Resolução 196/96 do Conselho Nacional de Saúde ${ }^{2}$. A coleta de dados, foi realizada através de observação participante com registro em diário de campo e entrevista semiestruturada.

Na primeira etapa, foram realizadas em torno de doze horas de observações junto a cada um dos profissionais pesquisados, acompanhando-os em suas atividades diárias, como consultas ambulatoriais e visitas hospitalares. A observação participante visava a descrever situações do contexto de trabalho, tanto do trato com colegas, pacientes e familiares, bem como com a equipe de saúde e residentes. Conforme Moré e Crepaldi (2004), os registros advindos de observações como essa apresentam informações fundamentais na construção de sentidos dos dados, oferecendo uma maior contextualização às análises realizadas, bem como promovem uma "aliança estratégica" entre o pesquisador e os sujeitos pesquisados, no sentido de melhor favorecer o fluxo das narrativas durante as entrevistas.

Já em um segundo momento, foram agendadas as entrevistas, em horário e local indicados pelo profissional, tendo sido as mesmas gravadas em áudio para preservar a fidedignidade dos relatos. As entrevistas abordaram questões relacionadas ao perfil do profissional (idade, estado civil, tempo profissão), às atividades diárias (mais desgastantes, que mobilizavam emocionalmente), aos sentimentos experienciados e às consequências dessas atividades na vida pessoal e profissional. Abordaram também as percepções sobre a oncologia clínica, bem como os recursos de enfrentamento psicológico utilizados cotidianamente.

Cabe ressaltar que as perguntas que envolviam as estratégias de enfrentamento psicológico eram precedidas por questões em que os profissionais tinham de descrever uma situação de difícil manejo na profissão ou em que

2 A pesquisa foi realizada antes da vigência da Resolução n ${ }^{\circ}$ 466/2012, motivo pela qual se embasa na resolução anterior. eram convidados a se reportarem às dificuldades por eles elencadas nas perguntas anteriores. Assim, as questões foram contextualizadas de acordo com a realidade e vivência dos participantes: quais as situações exigem do profissional mais do que conhecimento técnico, o que o profissional faz para lidar com essas situações, que emoções são mobilizadas, quais os modos de lidar com essas emoções, que atividades servem de suporte, qual o papel da espiritualidade no dia a dia, quais as formas e modos de lidar com os problemas profissionais e pessoais.

\section{Análise dos Dados}

A análise e organização dos dados obtidos seguiu os princípios da Teoria Fundamentada nos Dados (Cassiani, Caliri \& Pelá, 1996; Strauss \& Corbin, 2008; Yunes \& Szymanski, 2005), que possibilita combinar abordagens indutivas e dedutivas, permitindo trabalhar com informações oriundas de diversas fontes, como é o caso da entrevista e dos relatos de observação de campo. Para tanto, conforme proposto por Strauss e Corbin (2008), procedeu-se a sucessivas leituras do material coletado, visando à análise do conteúdo dos relatos dos participantes e do diário de campo, através de um movimento de leitura recursivo, com vistas a melhor integralizar os dados. Assim, por meio da codificação aberta, axial e seletiva, pretendeu-se integrar os dados, considerando a lógica das narrativas dos participantes da pesquisa.

É mister mencionar que, quando da emergência dos dados, decidiu-se pela nomeação das categorias utilizando como referência a proposta dos teóricos da Teoria do Enfrentamento Psicológico (Lazarus \& Folkman, 1984; Seidl, Tróccoli, \& Zannon, 2001), amplamente reconhecidos no contexto da produção de conhecimento. Desse modo, foram definidas as principais categorias de análise do estudo, sendo que desse processo de codificação resultou um conjunto de dados que possibilitou a compreensão integrada do fenômeno estudado: as estratégias de enfrentamento psicológico.

\section{Resultados e Discussão}

Os resultados encontrados reúnem as ações e os manejos (emocionais, psicológicos, comportamentais) que os profissionais utilizam frente à realidade em que estão inseridos e que, em seu conjunto, revelam as estratégias de enfrentamento psicológico dos médicos oncologistas. Destarte, os resultados foram agrupados em seis categorias, que se subdividem em subcategorias (desdobramentos da categoria principal) que contemplam a minuciosidade e a singularidade da produção de conhecimento na pesquisa qualitativa (González-Rey, 2002).

As quatro primeiras categorias, como dito anteriormente, foram organizadas conforme proposições teóricas da Teoria do Enfrentamento Psicológico (Lazarus \& Folkman, 1984; Seidl et al., 2001) e as duas últimas contemplaram estratégias que desempenham mais de uma função bem como uma avaliação do seu uso. Dividem-se, assim, em estratégias (a) focalizadas no problema, (b) focalizadas na emoção, (c) 
religiosidade/espiritualidade, (d) suporte social, (e) estratégia combinada e (f) autoavaliação de estratégias utilizadas.

Ao apresentar as categorias de análise, cabe apontar que essas foram didaticamente divididas para facilitar a compreensão dos dados. Porém, entende-se que as estratégias de enfrentamento psicológico não ocorrem de modo compartimentado, mas fazem parte de um funcionamento dinâmico e complexo, estando, portanto, sujeitas a constantes processos de avaliação/reavaliação. Os nomes dos participantes apresentados neste artigo são fictícios, visando a preservar a identidade dos profissionais.

\section{Focalizada no Problema}

Nessa categoria, foram agrupadas as estratégias em que a pessoa busca manejar, alterar, interferir na realidade, de modo a tentar modificar aquilo que lhe causa maior estresse ou ameaça. Entre as subcategorias de análise, foram observadas situações em que há tentativa de manejar, de resolver e de reavaliar a situação.

Percebe-se nos depoimentos que, diante de situações difíceis na prática médica, os profissionais buscam manejar o problema comunicando a situação às famílias, ou seja, enfrentando essas situações de modo ativo. Essas situações difíceis envolvem, por exemplo, a comunicação de diagnóstico reservado, relacionado a casos graves em que a doença continua progredindo apesar do tratamento ou diante de situações em que não há mais recurso terapêutico.

Isso, assim, de certa forma, é a prevenção daqueles eventos mais desagradáveis da nossa especialidade, que é você ouvir: 'eu não fui avisado que a doença era tão grave', 'eu não sabia que ele podia morrer'. Então, assim, quando eu tenho essa situação, que eu vejo que é mais crítica, que as pessoas não se situaram... eu gosto de chamar todos os envolvidos com a familia... (Renata)

Observa-se que o manejo frente a uma situação considerada mais crítica ocorre também para que os profissionais possam evitar problemas futuros, de modo que não sejam cobrados depois, na tentativa de não se sentirem responsáveis/culpados. Esse achado encontra reverberação nos apontamentos de Hanna et al. (2011), quando referem que os profissionais da área evitam se defrontar com questões que envolvem a morte. A comunicação nos casos mais graves aparece como algo extraordinário na profissão, como se não fizesse parte da prática clínica. Dessa forma, alguns profissionais relatam que, quando ocorrem essas situações, eles já se preparam antes e reservam um tempo especial para fazer a comunicação, como se essa fosse tarefa da alçada de outro profissional.

Ao analisar as entrevistas em sua totalidade, percebe-se que as mulheres enfatizaram mais a questão da comunicação, explicitando como fazem e o cuidado que elas têm diante dos pacientes. Nesse sentido, pode-se supor que existam diferenças entre os gêneros, o que poderia implicar diferentes estratégias de enfrentamento. Esses dados vão ao encontro do que propõem Millan et al. (2005) quando apontam que, com relação aos fatores de personalidade, as mulheres do âmbito médico apresentam tendência maior à sensibilidade se comparadas aos homens.
Como uma tentativa de melhor manejar a situação, os profissionais lançam mão de comportamentos obsessivos - voltados a uma excessiva organização, preocupação com detalhes e rigidez nas condutas que se traduzem em certa inflexibilidade - como, por exemplo, a adoção de rotinas organizadas, em uma tentativa de controlar os eventos cotidianos, especialmente de uma doença caracterizada pela imprevisibilidade: "Eu me organizo e costumo cumprir o horário. E me sinto mais tranquila quando eu consigo fazer isso... Eu tenho essa coisa de organizar, senão não funciona" (Renata); "A tentativa de organização é principalmente assim, procurar manter os horários para não, porque senão, dai sim, eu me estresso, se estou atrasada, se deixo alguma coisa para trás, isso me deixa estressada" (Maria).

Cabe ressaltar que, diante dos pacientes com possibilidades de cura ou daqueles que têm uma piora no estado geral, mas com os quais já se estabeleceu um vínculo - uma relação médico-paciente mais próxima - o oncologista lança mão de outras estratégias para enfrentar a situação da doença, na tentativa de acelerar o processo de tratamento/procedimento ou de buscar outros meios de intervenção, objetivando resolver a situação.

O paciente que tem possibilidades de cura é um paciente que vai fazer com que a gente tente ir atrás da tomografia mais rápida, do medicamento melhor, então eu acho que isso mobiliza. (Maria - Diário de campo)

Aqueles pacientes mais antigos, que você já conhece há mais tempo... Quando esses pacientes têm uma piora... você se sente penalizado também. Então você tenta uma coisa a mais. (Miguel - Diário de campo)

Esses apontamentos corroboram o estudo de Trindade et al. (2007) quando apontam que é bastante comum a adoção de uma atitude paternalista do médico oncologista diante de pacientes fora das possibilidades de recurso terapêutico. Ao que se pode acrescentar que essa atitude se faz especialmente presente nos pacientes com possibilidades terapêuticas e naqueles que já desenvolveram com seu clínico uma relação mais próxima.

A última subcategoria de análise das estratégias focalizadas no problema revela que os oncologistas, depois de alguns anos de profissão, reavaliam as situações da sua práxis, como se a experiência lhes oportunizasse uma nova visão, percepção da especialidade.

Se eu vejo uma situação muito difícil (...) eu vejo, assim, o contrário. Eu vejo a valorização das coisas boas. Então, coisas que eu sinto que os pacientes referem a mim, a dificuldade de comer, a dificuldade de dormir, a dificuldade de se locomover, como coisas básicas, que é básico para cada um, que é normal para cada um, eu vejo o valor que isso tem. (Tiago)

Depois de quase 30 anos... então você aprende a lidar melhor com isso... mas antes era assim resolver o problema deste paciente que se apresentava, dessa conjuntura, era mais importante do que tudo ... O que é que se compreende agora? Que sou um a mais dentro desta estrutura, que farei tudo o que estiver a meu dispor.. Tem coisas que são insolúveis. Talvez seja essa a grande descoberta, a aceitação de que existem coisas insolúveis. (Solange)

A reavaliação da situação também se observa em outras situações, como, por exemplo, diante de pacientes idosos. Os profissionais se valem da perspectiva de que, se o paciente 
já é mais velho, a doença não é tão ruim assim, afinal, esse idoso já viveu sua vida.

Talvez por aquela questão, assim, "puxa vida, ele vai morrer, nem viveu sua vida toda" e, por outro lado, "puxa vida, é, ele vai morrer, mas vai morrer com dignidade, 80 anos, teve filhos, teve netos, viveu sua vida". Mas talvez, do ponto de vista do paciente, não seja a mesma ideia... Talvez essa perspectiva, no geral, ajude. Mas, talvez não seja por aí. (Demétrio)

Esses dados apontam para resignificações das situações cotidianas no exercício médico e também diante dos eventos da vida privada. Os profissionais relatam a importância que passam a dar aos pequenos momentos, indicando que lidar com uma doença grave, com a dor e a morte, repercute no sentido de uma maior valorização da vida.

\section{Focalizada na Emoção}

As estratégias focalizadas na emoção têm como objetivo minimizar ou regular as respostas emocionais da pessoa frente às situações consideradas estressantes e de difícil manejo. Nessa categoria, foram evidenciadas quatro subcategorias: os recursos da atividade de lazer, o uso de medicação/fármaco e/ ou álcool, o recurso da evitação e as práticas de autocuidado.

Há que se considerar que é praticamente consenso entre os profissionais a questão da necessidade quanto ao uso desse tipo de estratégia de enfrentamento. Isso se torna muito evidente nos depoimentos, quando os oncologistas referem que é preciso "se desligar", desfocar a atenção, separar a vida profissional da vida privada e buscar uma tentativa de esquecer, amenizar, no sentido de melhor lidar com os sentimentos e emoções que são despertados.

Eu tento esquecer as coisas quando saio daqui de dentro...

Eu tento separar vida profissional de vida pessoal... mas eu tento, eu me esforço o possivel, e acho que consigo. Às vezes saio daqui e vou para casa e fico pensando ainda no caso do paciente, mas eu tento evitar isso aí. (Miguel)

Embora a gente procure "domar" estes sentimentos, que a gente não pode se envolver emocionalmente com os doentes, sob pena de não conseguir simplesmente mais trabalhar... Eu tenho um mecanismo automático de delete, que funciona na hora em que eu ponho o pé fora do local de trabalho, até por uma questão de saúde mental. (João)

Os trechos "eu tento", "eu tenho" e "eu não posso" revelam a necessidade de esquecer, "desligar-se", "deletar" as emoções e experiências vividas durante o dia de trabalho, o que aponta para o uso de mecanismos voltados ao apaziguamento das sensações. Com relação ao uso desse tipo de estratégia de enfrentamento, há que se pensar que, desde a formação, estas são, de certo modo, incitadas. Com efeito, de acordo com Quintana et al. (2004), os estudantes de medicina são incentivados a desenvolver o que se denominou calosidade emocional, ou seja, não se deter naquilo que lhes passa, para que, com o tempo, desenvolvam uma barreira de imunidade aos sentimentos e emoções que emergem do contexto.

Os oncologistas ainda citam o uso de atividades de lazer, os afazeres domésticos, a prática de atividade física, assistir à televisão e ter hobbies pessoais: "Ir para academia, pra mim, não é só uma questão de fisico, mas é uma questão para minha cabeça. Acho que uma das minhas válvulas de escape é a academia" (Maria); "A única coisa realmente que eu não penso, é televisão... isso me relaxa muito mais que música, porque música também a cabeça fica... eu adoro, e eu realmente consigo relaxar, e eu consigo me desligar" (Renata). Esses dados apontam na direção das evidências encontradas por Escribà-Agüir e Bernabé-Muñoz (2002) quando indicam que atividades físicas e de lazer estão entre as principais estratégias utilizadas pelos médicos, pois possibilitam desconectar-se da realidade profissional.

Ainda em uma tentativa de alcançar um "desligamento mental" da prática profissional, os profissionais apontaram o recurso da medicação e/ou uso de álcool, a exemplo dos relatos seguintes: "Ansiedade, dai eu preciso de Lexotan (risos)... Eu gosto de dormir bem, tenho sempre um Lexotan na gaveta, para os dias em que eu não consigo desligar" (Maria); "Tomar remédio é um deles, eu durmo, só durmo se eu tomar remédio, então eu tomo"... (Silvia); "Ocasionalmente, eu tomo algum ansiolítico" [refere que faz uso da medicação em média três dias da semana] (Manoel).

Esses dados vão ao encontro das afirmações de EscribàAgüir e Bernabé-Muñoz (2002) quando afirmam que o consumo de fármacos pelos médicos é apontado como uma forma de lidar com situações de muita tensão emocional e também como meio para reduzir o estresse laboral. Ainda como um recurso, os entrevistados referiram o uso de álcool: "Às vezes, se você sai e vai para uma festa, uma dose de uma bebida um pouquinho mais forte, só para liberar um pouco o ego. Mas é só nestas ocasiões" (Miguel); "É só a questão para relaxar. Assim, só não bebo todo dia, mesmo porque isso caracteriza aí um alcoolismo... Mas é uma prática que eu uso bastante, assim, e que também me relaxa" (Maria).

Outra estratégia desenvolvida pelos médicos oncologistas encontra-se relacionada a atitudes de esquiva, sendo que o recurso de evitação parece estar presente: "Um dos motivos que eu tirei licença (...) era para que a agenda se esvaziasse mesmo, para que estes pacientes que estão com a gente há muito tempo procurassem novas opções" (Solange); "Dormir... Dormir, eu tenho uma necessidade muito grande de dormir, e dormir para mim é uma saída. Dormir para mim é uma necessidade maior quando eu estou vivenciando um problema, uma ansiedade" (Tiago).

O fato de tirar licença e afastar-se do trabalho, assim como a necessidade de dormir diante de situações de conflito ou problemas, demonstra uma atitude voltada a evitar o contato com aquilo que se passa. Outra estratégia nesse sentido refere-se ao uso de humor negro, citado especialmente pelos profissionais que trabalham com cuidados paliativos. Esses achados apontam na direção do que propõe Nogueira-Martins (2003) quando afirma que atitudes de ironia, como o uso do humor negro, podem ser utilizadas como uma maneira de enfrentar as vicissitudes do cotidiano médico, especialmente, porque o seu uso pode evitar o processo de reflexão sobre as limitações e exigências da profissão.

A adesão e o zelo em relação a práticas de autocuidado, voltadas à atividade física, alimentação e lazer, também se fizeram presentes entre as estratégias focalizadas na emoção: "Eu tenho que fazer atividade fisica, eu tenho que me distrair, eu tenho que ver outras coisas, fazer outras coisas, ter lazer" (José). 
Nessa categoria, ainda se enquadram alguns sentimentos que funcionam como estratégias de enfrentamento voltadas ao apaziguamento das emoções, como raiva, irritação diante do paciente e culpa - tanto sentir-se culpado, como culpar os outros e o paciente. Os sentimentos aqui referidos foram trabalhados e discutidos em uma categoria própria contemplada na dissertação que originou este artigo, devido à relevância e magnitude do tema.

Diante da exposição das estratégias focalizadas na emoção, há que se considerar que os autores (Blandin \& Araujo, 2005; Congrains, 1998; Tamayo \& Troccóli, 2002) apontam que o seu uso encontra-se relacionado à maior incidência de síndromes relacionadas ao estresse, como o Burnout. Assim, as estratégias que têm por objetivo provocar uma liberação dos conteúdos mentais e emocionais, foram por Blandin e Araujo (2005) classificadas como disfuncionais, pois não respondem, de modo satisfatório, sendo o apaziguamento das emoções uma resposta situacional e, na maioria das vezes, com efeitos momentâneos.

\section{Religiosidade/Espiritualidade}

Essa categoria agrupa os pensamentos e comportamentos religiosos e/ou voltados à espiritualidade que possam estar sendo utilizados como uma estratégia para lidar com determinada situação ou evento do cotidiano. Para melhor compreensão dos termos utilizados, as autoras compartilham a definição de Lukoff (como citado por Faria \& Seidl, 2005) quando refere que religiosidade designa a adesão a crenças e práticas ligadas a uma instituição religiosa organizada, e a espiritualidade, a relação que a pessoa estabelece com um ser ou força superior em que acredita.

A adoção de uma prática religiosa não parece não ser algo enfatizado nas falas dos entrevistados. Não obstante, percebe-se que alguns apresentam certa espiritualidade não ligada a nenhuma religião formal ou instituída, mas a uma força superior ou mesmo energia: "Digamos que eu acredite numa força superior, mas não acredito no deus que o paciente usa, no deus que as pessoas tentam usar ao seu bel-prazer" (Solange); "Agora vou te ser bem sincera, eu me considero uma pessoa espiritual sim. Mas eu não sou assim, como eu te diria, não adoro um deus determinado" (Regina); "Eu sou católico... eu creio em Deus, eu rezo, uma coisa... eu acho que é uma âncora, muitas vezes, importante, você tem que ter uma esperança, uma fé que... Em tudo na vida" (José).

Assim, observaram-se duas situações: uma em que a religiosidade ou a espiritualidade estavam presentes, e outra em que se verificava a ausência de crenças ou práticas: "Não acredito mais em religião nenhuma. Acho sinceramente que na verdade o ser humano não precisa de religião para viver, até compreendo que muitas pessoas sintam necessidade" (Miguel).

Interessante ressaltar que alguns profissionais, diante da sua atitude de descrença, afirmam que gostariam muito de poder acreditar em algo superior e demonstram iniciativas na tentativa de alcançarem alguma fé, possuírem alguma crença: "Eu gostaria de ter mais fé, uma fé sólida. Talvez isso fosse mais um amparo para mim, para ter um interior mais estável. Mas eu não consigo" (Demétrio).
Ao final da exposição dessa categoria, cabe apontar que se destacou entre os oncologistas entrevistados a ideia de que o deus do paciente é um deus diferente, sendo que, em certos momentos, descrevem-no como algo caricato (aquele deus de barbinha branca, tradicional, que vai passar a mão por cima). Tal fato pode estar relacionado aos aspectos que embasam a profissão médica, como a objetividade, a previsibilidade e a controlabilidade, de modo que a crença alude a algo não palpável, portanto difícil de ser auferido ou comprovado.

\section{Suporte Social}

Essa categoria reúne as estratégias em que a busca por suporte social, seja através de apoio instrumental, emocional ou de informações, caracteriza-se como um recurso de enfrentamento psicológico, exercendo função de apoio, suporte, no sentido de fornecer sustentação. Nessa categoria, foram evidenciadas quatro subcategorias: apoio familiar, apoio de colegas/institucional, apoio instrumental/ profissional e sentido negativo - afastamento social/ isolamento.

Os dados encontrados sugerem que a busca de apoio social varia conforme a situação. Constata-se, assim, que é mais comum o profissional buscar apoio social recorrendo aos colegas quando o problema se refere a algo do trabalho. Por outro lado, quando o problema ou dificuldade é de ordem pessoal, é mais usual encontrar a busca por suporte em um profissional especializado, como um analista ou psicólogo, por exemplo.

Com relação ao apoio familiar, os resultados indicam que o apoio de familiares e amigos é comum, principalmente voltado ao suporte emocional, no sentido de apaziguar as angústias e emoções: "Sempre gostei de reunir muita gente dentro de casa... Eu estou sempre arranjando uma desculpa para chamar alguém, para fazer comida, para beber, para contar estórias, de preferência que não tenha nada a ver com medicina, né!” (Maria); "Muitas vezes, meu próprio companheiro me ajuda a resolver algumas coisas, ou uma amiga, de repente a gente conversa" (Regina); "Ter um círculo de amizades diferente da área profissional é importante... aquelas situações em que eu me incomodo... eu acabo conversando sobre isso com a minha mulher também. É uma maneira de ela sempre me convencer de que não tem problema, que é assim... (risos) de dar um apoio... eu sempre divido isso com ela" (Nelson).

O suporte familiar relacionado aos cônjuges aponta que um dos aspectos positivos refere-se ao fato de o companheiro não ser da área médica, o que explicita a necessidade de um suporte diferenciado, de uma pessoa que não funcione na mesma lógica médica, da racionalidade e objetividade. Nesse sentido, conforme Woodward (2005), quando o esposo(a) do cônjuge médico é de outra área, acaba assumindo algumas tarefas, possibilitando maior suporte para que o outro possa exercer a profissão, a exemplo do relato seguinte: " $A$ melhor coisa pra mim foi ter me casado pela segunda vez com uma pessoa que não é médica. Porque não me é exigido falar do paciente, bem pelo contrário, ele não sabe nem o que perguntar" (Silvia). 
A segunda subcategoria - apoio de colegas/institucional - refere-se às situações em que, diante das dificuldades relacionadas à sua profissão ou a algum paciente, os profissionais dividem a responsabilidade com os outros: "Relacionado com questões do meu trabalho (...) Eu recorro aos colegas mais próximos que eu confio... outros médicos mais experientes" (Nelson); "Procuro ouvir a opinião de outras pessoas, procuro não decidir sozinho, se eu tenho dúvida, procuro ouvir um colega ou dois ou três, ou quantos forem necessários" (João).

Os depoimentos ilustram que o apoio de colegas da instituição funciona como uma estratégia focalizada no problema, quando utilizado para solucionar alguma questão específica, ou como uma estratégia focalizada na emoção, pois dividir com o colega auxilia a repartir as angústias, trazendo conforto e sustentação emocional: "Eu consigo me abrir com a equipe, às vezes, até é meio chocante, porque as pessoas não esperam muito. (...) Eu acho que eu devo sobrecarregá-las, mas é com a equipe geralmente" (Renata).

A terceira subcategoria - apoio instrumental/profissional - refere-se ao suporte social que se estabelece por meio de uma ajuda especializada, seja de um profissional, como o psicólogo ou psiquiatra, seja por meio de um instrumento, como livros ou cursos. A busca por material bibliográfico auxilia a instrumentalizar para a prática, no sentido de auxiliar a resolver as demandas clínicas: "Se tenho algum caso mais dificil que eu tenho que resolver.. eu estudo e me preparo do ponto de vista profissional. Vou atrás de bibliografia" (Regina).

O suporte através de ajuda especializada também foi evidenciado como necessário por alguns oncologistas, devido à dificuldade de partilhar aspectos da vida privada e em função das conjunturas pessoais. Assim, percebe-se que a terapia auxiliou o profissional a reavaliar situações da vida e consequentemente da profissão relacionadas ao estilo de vida, possibilitando também que algumas dificuldades do cotidiano fossem canalizadas de outras formas que não por meio de conflitos com as outras pessoas: "Eu sou uma pessoa bastante fechada... eu não falo com ninguém... me isolo na minha vida pessoal. Então, eu tive que fazer análise e faço e me sinto muito bem. É onde...eu tenho meu suporte" (Silvia); "Antigamente eu brigava... Com todos que eu julgasse responsáveis por aquela situação. Mas atualmente é terapia" (Solange).

A última subcategoria - suporte social no sentido negativo, ou seja, de afastamento social e isolamento apresenta situações em que ocorre justamente o oposto: o afastamento social, inclusive havendo uma tentativa de vigilância para que não ocorra a expressão dos sentimentos perante as outras pessoas e/ou meio: "Eu acho que eu tenho uma tendência a isolamento. Eu não sou um ser muito social, eu acho que isso é fruto do que eu faço" (Renata). Um dos pontos que merece atenção é que, diante do afastamento social, o profissional parece preocupar-se com a possibilidade de estar incomodando o outro ao falar e dividir seus problemas. Desse modo, há uma tentativa de não falar, de evitar falar sobre o trabalho e há um vigiar-se para que a expressão desses sentimentos não apareça: "Eu tento evitar, principalmente na minha casa. A não ser que eu chegue muito atingida" (Regina); "Eu não vou sair daqui para conversar com alguém e falar sobre o sofrimento do paciente tal, sobre o sofrimento dos familiares, sobre o sofrimento de todo mundo que estava em volta olhando. Ah não" (Miguel). O controle para não expressar sentimentos fora do contexto profissional ganha respaldo nas colocações de Quintana et al. (2004) quando sugerem que a repressão dos sentimentos é incentivada já durante a graduação em medicina, devendo iniciar entre colegas e professores.

Cabe ressaltar que o não falar do trabalho é necessário sob o ponto de vista da ética médica. Essa postura desconsidera, entretanto, que os próprios médicos podem ser atingidos ao tentarem ignorar esse sofrimento, percebendo que a sua expressão passa a ser algo velado em outros ambientes. Contudo, esse esforço, muitas vezes, não alcança êxito e a tentativa de dividir essas vivências acaba ocorrendo em momentos pouco adequados, até mesmo porque, diante do isolamento, é como se essas sensações e sentimentos extravasassem sem que a pessoa se dê conta.

É uma coisa mais comum impossível... a gente acaba levando os problemas para casa... Eu falo sim. Bastante. E, às vezes, até quando eu estou em outros grupos. Eu tenho que me cuidar, porque dai, eu às vezes, já me vejo tomando conta da conversa. Contando uma desgraça total, assim, e aquilo é uma coisa tão natural, mas que eu acho horrivel, quando eu me dou conta, meu Deus... tu não tens condições realmente, porque é horrivel aquilo. (Renata)

Os dados relativos ao suporte social sugerem que essa é uma estratégia presente, aludindo à necessidade da existência de espaços de troca - tanto para trocas técnicas como de sentimentos - pois, apesar do esforço em retê-los, esses acabam sendo extravasados, seja de maneira adequada ou inadequada.

\section{Estratégia Combinada}

Essa categoria agrupa as estratégias de enfrentamento psicológico que atendem a mais de uma função. São estratégias combinadas. Assim, podem tanto ser focalizadas no problema como na emoção. $\mathrm{O}$ uso da racionalização foi apontado nessa categoria por se entender que a busca por explicações e a racionalização dos fatos cotidianos são utilizadas tanto em uma tentativa de responder e dar soluções aos eventos, como para neutralizar os sentimentos e sensações emocionais.

Eu acho que o tempo faz a gente, talvez, racionalizar um pouco mais de uma forma com dó, às vezes, porque a racionalidade que nós temos lá no início da nossa carreira é a carapaça... eu consigo racionalizar o que ele tá sentindo, até aonde eu posso ir. Porque eu também não posso me entregar ao paciente e depois me retirar. Então, tem que saber exatamente até aonde (Silvia).

O uso da racionalização, voltada à tentativa de resolução do problema, acaba sendo um modo de lidar com as outras situações da vida. Conforme Meleiro (2005), o jovem médico incorpora comportamentos científicos, frios e de neutralidade, muitas vezes, generalizando-os para outras situações, independentemente do seu contexto.

A gente, como médico, atua no seguinte sentido... recebe um problema e procura uma solução... Então, muitas vezes, dentro de casa não é esse o caso, sei lá. (...) Tipo assim uma mentalidade 
resolutiva, que nem sempre é o caso. A pessoa não quer solução nenhuma, ela quer apenas que alguém escute, entenda. (João) Ainda com o objetivo de melhor resolver as demandas da profissão, a racionalização aparece através da focalização nos problemas do paciente, no que se refere à parte física desses problemas. Conforme apontam, isso os auxilia no raciocínio e nas decisões clínicas, ao mesmo tempo em que evita maior envolvimento com aspectos subjetivos.

Eu sou bastante objetiva com o paciente. (...) Então na minha vida privada também. Eu não consigo lidar com pessoas que falam muito (...) Eu vou direto ao assunto e tento resolvê-lo. ... E em casa também sou assim, não consigo lidar com pessoas que começam a conversar e dar muita volta. (Regina)

A racionalização, seja pelo fato de ter sido apreendida, incentivada na formação médica, ou, ainda, por ser uma estratégia derivada de condutas pessoais, apresenta certa disfuncionalidade no momento em que é utilizada em várias situações de modo indiscriminado. E, mesmo que ofereça alguma proteção emocional no sentido de resguardar o profissional, requer muita energia para que a pessoa esteja sempre mantendo tudo sob o controle.

\section{Autoavaliação de Estratégias Utilizadas}

Essa categoria agrupa as estratégias que foram apontadas pelos profissionais como ineficazes e que, em última análise, foram consideradas disfuncionais, seja porque não trazem mais o mesmo benefício seja pelo fato de serem percebidas como inapropriadas. Encontram-se, assim, duas subcategorias: Estratégias focalizadas na emoção e Psicoterapia/apoio instrumental.

Entre as estratégias focalizadas na emoção, o consumo de tabaco, bem como o de álcool, foi apontado pelos entrevistados como um recurso já utilizado, porém descartado após uma reavaliação pessoal, seja por ineficácia seja por julgarem essas estratégias pouco saudáveis.

Aí bebia vinho, mas não gostei, não gostei. ... quem nunca bebeu não tem uma habilidade para beber e fica muito fragilizado com uma taça de vinho. Agora, eu fumava. Eu fumava, essa era a válvula de escape. Mas então eu parei com isso. (Solange)

Eu tomava, bebia, vinho que eu gosto... Claro que isso chegou um ponto que foi demais. Que você para e pensa, mas por que eu tô tomando? (...) não é só porque eu gosto, porque foi uma semana muito estressante, né. (Silvia)

Quanto ao uso de álcool, também apontado como ineficaz, um dos profissionais afirmou que, apesar de seu uso em grande quantidade, ele não conseguia relaxar: por mais alcoolizado que estivesse, continuava preocupado e pensando, sem conseguir promover um desligamento da realidade.

A outra subcategoria aponta que a própria psicoterapia ou análise, enquanto apoio instrumental, pode ser considerada uma prática não efetiva: “Eu já fiz análise um tempo, mas eu achei que não foi efetivo (...) meu analista dizia que era muito importante. ... mas eu não consegui manter assim, isso faz muitos anos" (Renata). Esse apontamento encontrase relacionado à possibilidade de buscar auxílio e suporte de terceiros, como referido na categoria Suporte Social. Portanto, cabe apontar que, se os profissionais são instigados a não demonstrarem sentimentos, a prática da psicoterapia ou análise pode estar sendo considerada não eficaz, visto que o profissional não consegue expor e/ou dividir seus conflitos internos.

Convém observar que as estratégias de enfrentamento bem como a sua auto-avaliação são atravessadas pelas concepções pessoais e se relacionam e se organizam conforme a estrutura psíquica de cada entrevistado. Nesse sentido, Carvalho (2006), afirma que diferenças pessoais determinam reações distintas.

\section{Considerações Finais}

Os dados obtidos nesta pesquisa evidenciaram situações e demandas profissionais que exigem habilidades, muitas vezes, não contempladas no período de formação médica. Os médicos desenvolvem suas ações em um tensionamento extremo no processo de vida e morte, o que se traduz em um intenso desgaste emocional, motivo pelo qual se evidencia a utilização das mais variadas estratégias de enfrentamento psicológico. Estratégias que foram sendo, de certa maneira, construídas e incorporadas a partir da prática profissional com o intuito de melhor manejar e lidar com as diferentes situações vivenciadas.

Nesse sentido, a própria entrevista foi apontada, por alguns profissionais, como um suporte, um recurso, pois, conforme eles, o fato de estarem sendo ouvidos os confortava, e falar sobre as temáticas abordadas possibilitou uma reflexão e análise sobre a práxis profissional. Esse dado sugere e confirma os dados da literatura pesquisada, pois assinala a necessidade de autorreflexão, apoio e suporte social, o que pode favorecer uma melhor adaptação às demandas e exigências da profissão.

Entretanto, percebe-se que os profissionais com menos de cinco anos de profissão que participaram deste estudo apresentaram maior dificuldade para referir que recursos/ estratégias utilizam no cotidiano, frente a suas práxis. Esse achado pode sugerir que, quanto maior o tempo de experiência profissional, maior a clareza e conhecimento do profissional a respeito daquilo que lhe passa. Com efeito, a experiência permite reavaliar a própria profissão, bem como as experiências da vida privada, o que facilita o desenvolvimento e a atuação do oncologista.

As estratégias focalizadas no problema, como aquelas que dizem respeito à avaliação e aceitação de que a medicina é uma ciência imprevisível e que talvez existam situações de difícil resolução, estão entre as principais constatações que decorreram do tempo e da experiência profissional dos participantes deste estudo. Apesar disso, a frequência dos relatos apontando as estratégias focalizadas na emoção pode indicar maior incidência de estresse, visto que as mesmas não interferem na realidade, apenas produzem um apaziguamento frente às sensações de desconforto e mal-estar.

Ainda com relação às estratégias utilizadas, percebese não predominar, entre os participantes, uma crença em alguma religião instituída, mas a presença de uma relação com alguma força superior ou energia, sendo que há relatos de profissionais que gostariam de possuir maior vinculação ou, até quem sabe, acreditar no "deus do paciente". Do 
mesmo modo, a prática do suporte social aparece relacionada aos aspectos da profissão e, dificilmente, aos aspectos emocionais, no sentido de suporte pessoal.

Diante do exposto, a racionalização, estratégia combinada, acaba sendo utilizada de modo indiscriminado, de forma que seu uso acaba se estendendo inclusive para a vida privada. Assim, a última categoria apresentada, avaliação das estratégias, ganha destaque, pois se evidencia que os profissionais buscam alguma estratégia que seja "eficaz", para que possam "se desligar" e abrandar as emoções experimentadas cotidianamente.

Portanto, tendo em vista as inúmeras estratégias de enfrentamento utilizadas, enfatiza-se a necessidade de espaços de acolhimento e escuta para o profissional. Nessa mesma linha, propõe-se o uso da supervisão, no sentido psicológico, como uma atividade a ser desenvolvida desde a formação médica. Acredita-se que, ao assumir o lugar de alguém que detém o conhecimento sobre uma doença - desconhecida e também temida diante pelo paciente -, o profissional acaba sendo investido de expectativas às quais não tem condições de responder, especialmente pois estas envolvem questões como a imprevisibilidade. Soma-se a isso, a falta de aptidão e treinamento de habilidades sociais e de relacionamento interpessoal e comunicacional, que acaba conduzindo o profissional às mais diversas saídas - desde a não comunicação do diagnóstico, ao uso da despersonalização - tão nocivas à relação com o paciente e que revelam o despreparo diante da tarefa de "cuidar" e não somente "curar".

Entretanto, ao não se defrontarem com as angústias e os sentimentos gerados pela prática oncológica de modo coletivo, no sentido de todos reconhecerem que essas são questões inerentes à prática do médico e não dificuldades de cunho pessoal - estas acabam sendo vivenciadas de modo solitário. Observa-se que a falta de um sentimento de coletividade interfere na busca por "saídas" mais amplas e contextuais, que poderiam envolver alterações curriculares e na formação médica. Assim, o que se observa é que as estratégias utilizadas, vivenciadas na individualidade de cada pessoa, não interferem ou pouco impactam o social e coletivo da classe médica, pois, de fato, tangenciam uma importante questão a ser trabalhada: a humanidade do próprio médico.

Diante disso, torna-se necessária a presença dos dispositivos de prevenção e promoção à saúde, seja nas formações e residências médicas, seja nas entidades de classe e nas políticas de saúde do trabalhador. Tudo isso, com vista a proteger a saúde mental dos profissionais, o que reverterá num melhor acolhimento das demandas por eles recebidas. Por fim, cumpre ressaltar que os dados encontrados sugerem que sejam organizadas outras investigações que possam considerar variáveis como a personalidade dos profissionais, tendo em vista que todas as estratégias de enfrentamento se estruturam com base em experiências pessoais e encontramse calcadas na subjetividade de cada profissional. Cabe considerar, também, o tempo de experiência profissional e a especialidade médica, podendo ser realizados estudos com diferentes especialidades, em especial aquelas em que o profissional estabelece contato frequente com os pacientes, sendo responsável pelo seu acompanhamento clínico.

\section{Referências}

Blandin, J., \& Araujo, D. M. (2005). Estrés laboral y mecanismos de afrontamiento: Su relación en la aparición del Síndrome de Burnout en médicos residentes del Hospital Militar "Dr. Carlos Arvelo". Archivos Venezolanos de Psiquiatria y Neurologia, 51(104), 12-15.

Campos, E. P. (2005). Quem cuida do cuidador: Uma proposta para os profissionais de saúde. Petrópolis, RJ: Vozes.

Cano, D. S. (2008). O profissional que está no fio - entre a vida e a morte: Vivências, Concepções e Estratégias de Enfrentamento Psicológico de médicos oncologistas. (Dissertação de Mestrado). Universidade Federal de Santa Catarina, Florianópolis.

Carvalho, V. (2006). A equipe de saúde e suas vicissitudes emocionais. In C. A. M. Pimenta, D. D. C. F. Mota \& D. A. L. M Cruz (Orgs.), Dor e cuidados paliativos: Enfermagem, medicina e psicologia (pp. 103-123). São Paulo: Manole.

Cassiani, S. H. B., Caliri, M. H. L., \& Pelá, N. T. R. (1996). A teoria fundamentada nos dados como abordagem da pesquisa interpretativa. Revista Latino-Americana de Enfermagem, 4(3), 75-88. doi: https://dx.doi.org/10.1590/ S0104-11691996000300007

Congrains, J. A. (1998). Modos de afrontamiento al estrés en residentes de medicina. Revista Medica Herediana, 9(2), 63-68.

Escribà-Agüir, V., \& Bernabé-Muñoz, Y. (2002). Estrategias de afrontamiento ante el estrés y fuentes de recompensa professional en médicos especialistas de la comunidad Valenciana: Un estudo con entrevistas semiestructuradas. Revista Española de Salud Pública, 76(5), 595-604.

Faria, J. B. \& Seidl, E. M. F. (2005). Religiosidade e enfrentamento em contextos de saúde e doença: Revisão da literatura. Psicologia: Reflexão e Crítica, 18(3), 381-389. doi: https:// dx.doi.org/10.1590/S0102-79722005000300012

Glasberg, J., Horiuti, L., Novais, M. A. B., Canavezzi, A. Z., Miranda, V. C., Chicoli, F. A., Gonçalves, M. S., Bensi, C. G., \& Del Giglio, A. (2007). Prevalence of the burnout syndrome among brazilian medical oncologists. Revista da Associação Médica Brasileira, 53(1), 85-89. doi: https://dx.doi. org/10.1590/S0104-42302007000100026

Gomes, C. H. R., Silva, P. V., \& Mota, F. F. (2009). Comunicação do Diagnóstico de Câncer: Análise do comportamento médico. Revista Brasileira de Cancerologia, 55(2), 139-143.

González- Rey, F. L. (2002). Pesquisa qualitativa em psicologia: Caminhos e desafios. São Paulo: Pioneira Thomson Learning.

Graham, J. (2000). Stress and burnout an oncology. Oncology, 14(11), 1-4.

Hanna, S. A., Marta, G. N., \& Santos, F. S. (2011). O médico frente a novidades no tratamento do câncer: quando parar? Revista da Associação Médica Brasileira, 57(5), 588-593. doi: https:// dx.doi.org/10.1590/S0104-42302011000500020

Lazarus, R. S., \& Folkman, S. (1984). Stress, appraisal, and coping. New York: Springer.

Lozano, J. A. F. (2007). Combatir el burnout del pediatra: Prevención y control. Canarias Pediátrica, 31(2), 119-123.

Jiménez, J. P. (2005). Estrategias de los medicos para hacer frente a la crisis de la profesión. Revista Médica do Chile, 133, 707-712. doi: http://dx.doi.org/10.4067/S0034-98872005000600014

Meleiro, A. A. S. (2005). O médico como paciente (2a ed.) São Paulo: Segmento-Farma. 
Millan, L. R., Azevedo, R. S., Rossi, E., De Marco, O. L. N., Millan, M. P. B., \& Arruda, P. C. V. (2005). What is behind a student's choice for becoming a doctor? Clinics, 60(2), 143-150. doi: https://dx.doi.org/10.1590/S1807-59322005000200011

Moré, C. L. O. O., \& Crepaldi, M. A. (2004, março). O campo de pesquisa: Interfaces entre a observação, interação e o surgimento dos dados. $1^{a}$ Conferência Internacional do Brasil de Pesquisa Qualitativa/NPF-Núcleo de Pesquisa da Família. Taubaté, São Paulo, Brasil.

Nogueira-Martins, L. A. (2003). Saúde mental dos profissionais de saúde. Revista Brasileira de Medicina do Trabalho, 1(1), 56-68.

Nogueira-Martins, M. C. F. (2001). Humanização das relações assistenciais: A formação do profissional de saúde. São Paulo: Casa do Psicólogo.

Paris, L., \& Omar, A. (2008). Predictores de satisfacción laboral en médicos y enfermeros. Estudos de Psicologia (Natal), 13(3), 233-244. doi: https://dx.doi.org/10.1590/S1413294X2008000300006

Pitta, A. M. F. (2003). Hospital: Dor e morte como oficio (5a ed). São Paulo: Annablume/Hucitec.

Quintana, A. M., Rodrigues, A. T., Goi, C. M. D., \& Bassi, L. A. (2004). Humanização e estresse na formação médica. Revista AMRIGS, 48(1), 27-31.

Resolução no 196, de 10 de outubro de 1996. - Dispõe sobre pesquisas envolvendo seres humanos. Retirado de: http:// conselho.saude.gov.br/web comissoes/conep/aquivos/ resolucoes/23_out_versao_final_196_ENCEP2012.pdf

Roger, M. C., Abalo, J, G., Guerra, M. E., \& Pérez, C. M. (2006). Afrontamientos y emociones en profesionales de enfermaria oncológica con síndrome de desgaste professional. Psicología y Salud, 16(2), 115-128.

Sá, M. R. C. (2000). A modernidade desencantada, a crise da medicina e o imaginário institucional. Revista Brasileira de Educação Médica, 24(3), 46-52.
Sampieri, R. H., Collado, C. F., \& Lucio, P. B. (1991) Metodologia de la investigación. México: McGraw-Hill.

Seidl, E. M. F., Tróccoli, B. T., \& Zannon, C. M. L.C. (2001). Análise fatorial de uma medida de estratégias de enfrentamento. Psicologia: Teoria e Pesquisa, 17(3), 225-234.

Silva, C. M. G. C. H., Rodrigues, C. H. S., Lima, J. C., Jucá, N. B. H., Augusto, K. L., Lino, C. A., Carvalho, A. G. N., Andrade, F. C., Rodrigues, J. V., \& Caprara, A. (2011). Relação médico-paciente em oncologia: medos, angústias e habilidades comunicacionais de médicos na cidade de Fortaleza (CE). Ciência \& Saúde Coletiva, 16(Suppl. 1), 1457-1465. doi: https://dx.doi.org/10.1590/S1413-81232011000700081

Silva, R. A. R., Souza Neto, V. L., Oliveira, G. J. N., Silva, B. C. O., Rocha, C. C. T., \& Holanda, J. R. R. (2016). Estratégias de enfrentamento utilizadas por pacientes renais crônicos em tratamento hemodialítico. Escola Anna Nery, 20(1), 147-154. doi: https://dx.doi.org/10.5935/1414-8145.20160020

Strauss, A., \& Corbin, J. (2008). Pesquisa qualitativa: Técnicas e procedimentos para o desenvolvimento da Teoria Fundamentada (2a ed.). Porto Alegre: Artmed.

Trindade, E. S., Azambuja, L. E. O., Andrade, J. P., \& Garrafa, V. (2007). O médico frente ao diagnóstico e prognóstico do câncer avançado. Revista da Associação de Médica Brasileira, 53(1), 68-74. doi: https://dx.doi.org/10.1590/ S0104-42302007000100023

Woodward, C. A. (2005). When a physician marries a physician: Effect of physician- physician marriages on Professional activities. Canadian Family Physician, 51, 851- 857.

Yunes M. A. M., \& Szymanski, H. (2005). Entrevista reflexiva e grounded-theory: Estratégias metodológicas para compreensão da resiliência em famílias. Interamerican Journal of Psychology, 39(3), 431-438.

Zonta, R., Robles, A. C. C., \& Grosseman, S. (2006). Estratégias de enfrentamento do estresse desenvolvidas por estudantes de medicina da Universidade Federal de Santa Catarina. Revista Brasileira de Educação Médica, 30(3), 147-153. doi: https:// dx.doi.org/10.1590/S0100-55022006000300005

Recebido em 21.08.2013

Primeira decisão editorial em 11.04.2016

Versão final em 10.05.2016

Aceito em 19.07.2016 